\title{
Antibacterial and antifungal activity of MTA-based root canal sealer versus epoxy resin-based and methacrylate resin-based sealers
}

\author{
Ali Türkyılmaz ${ }^{1}$, Ali Erdemir ${ }^{2}$ \\ ${ }^{1}$ Kırıkkale University, Faculty of Dentistry, Department of Endodontics, Kırıkkale, Turkey
}

\section{Correspondence:}

\section{Dr. Ali TÜRKYILMAZ}

Kırıkkale University, Faculty of Dentistry, Department of Endodontics, Kırıkkale, Turkey.

E-mail:turkyilmaz_a@hotmail.com

Received: 03 October 2019

Accepted: 18 April 2020

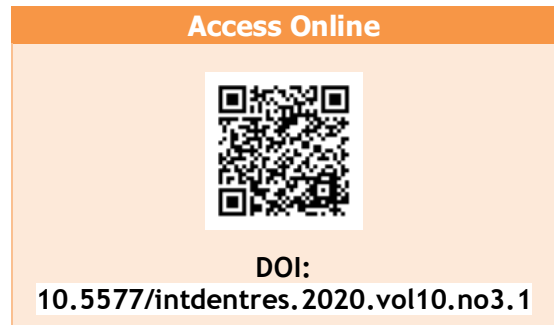

\section{Introduction}

Endodontic therapy aims to eliminate residual pulp, microorganisms, and by-products, followed by a hermetic obturation to prevent reinfection inside the root canal system (1). Root canal sealers can provide sealer.
Aim: The purpose of this study was to compare the antibacterial and antifungal activity of MTA Fillapex with AH 26, AH Plus, and RealSeal root canal sealers. S. aureus, E. faecalis, and C. albicans were used as test microorganisms with the agar-diffusion test (ADT) and the direct contact test (DCT).

Methodology: For the ADT, 48 Mueller-Hinton plates were divided into 3 groups according to the microorganism used. Each group was then divided into 4 subgroups according to root canal sealer. Mueller-Hinton and Sabouraud agar mediums were preferred, and inhibition zones were measured to determine the antimicrobial efficacy at designated intervals. In the DCT, 96-well microtiter plates were used. For each microorganism and each sealer, 8 consecutive wells were prepared vertically on the plate. Microbial suspensions were allowed to directly contact the sealers in each well for 1 hour at $37^{\circ} \mathrm{C}$. Subsequently, microbial growth was spectrophotometrically measured at set intervals for the freshly mixed and set forms.

Results: A statistically significant difference was found between the tested root canal sealers for antimicrobial effectiveness $(p<0.05)$. According to the ADT results, all sealers had antimicrobial activity against the tested microorganisms. MTA Fillapex demonstrated satisfying results in the ADT against all microorganisms. In the DCT, MTA Fillapex inhibited bacterial and fungal growth in all freshly mixed and set forms. However, the set forms of $\mathrm{AH} 26$ and AH Plus began to lose their antimicrobial activity on the tested microorganisms after a while.

Conclusion: The results showed that the MTA-based root canal sealer MTA Fillapex may be a favorable alternative sealer against bacterial and/or fungal species in clinical practice.

Keywords: Antifungal, antimicrobial, MTA Fillapex, RealSeal, root canal

How to cite this article: Türkyılmaz A, Erdemir A. Antibacterial and antifungal activity of MTA-based root canal sealer versus epoxy resin-based and methacrylate resin-based sealers. Int Dent Res 2020;10(3):66-72.

https://doi.org/10.5577/intdentres.2020.vol10.no3.1 an impermeable sealing as a filler for irregularities and between the root canal wall and core material. Sealing ability, biocompatibility, and antimicrobial activity are important properties for root canal sealers. The antimicrobial activity of a sealer might help to reduce or inhibit the growth of the remaining microorganisms 
when pulpal necrosis and apical periodontitis are present (2).

Staphylococcus aureus, Enterococcus faecalis, and Candida albicans are considered the most resistant facultative microorganism species in the oral cavity and can cause unsuccessful treatment results (3). S. aureus can be isolated from acute dentoalveolar infections, such as dental abscesses (4). E. faecalis is the most commonly isolated pathogen from endodontic infections, ranging from 24 to $77 \%$ (5), and is associated with persistent periradicular lesions after endodontic treatment (6). Similarly, C. albicans is the most commonly detected fungal species in the oral cavity of both healthy and medically supported individuals (7); it has been reported in primary, persistent, and secondary endodontic infections $(8,9)$.

AH Plus (Dentsply, Konstanz, Germany) is an epoxy resin-based sealer that has the same physical and chemical properties as $\mathrm{AH}$ 26. In a study, it is reported that both $\mathrm{AH}$ Plus and $\mathrm{AH} 26$ have antimicrobial activity on various microorganisms (10). On the other hand, these root canal sealers have been shown to have highly, moderately, or slightly toxic effects in different studies $(11,12)$. RealSeal (SybronEndo, Orange, CA, USA) is a methacrylate resin-based root canal sealer. It has a Resilon 'monoblock' system introduced as an alternative obturation against an $\mathrm{AH}$ Plus/gutta percha combination. However, there are few studies in the literature about its antimicrobial activity.

MTA Fillapex (Angelus, Londrina, Brazil) is a recently developed endodontic sealer that claims to retain the biological and physical properties of mineral trioxide aggregate (MTA) (13). In this way, it may utilize the advantages of MTA as a permanent root canal sealer (14). According to the manufacturer, MTA Fillapex has a sufficient working time, high radiopacity, and is easy to handle. MTA Fillapex has a high $\mathrm{pH}$, solubility, and calcium ion release (15). Alkaline $\mathrm{pH}$ and solubility may benefit the antibacterial activity of MTA Fillapex.

The antimicrobial activity of root canal sealers can be evaluated using different methods. The agar diffusion test (ADT) is a method that is still used, though it has limitations (16). The direct contact test (DCT) investigates the effect of direct and close contact on microorganisms and tested materials. The DCT can also be used to test the endodontic sealers in various setting forms (17).

The aim of this in vitro study was to compare both the antibacterial and antifungal activity of the MTA Fillapex sealer against epoxy resin-based and methacrylate-based sealers.

\section{Materials and Methods}

The compositions of the sealers that were tested in the study are listed in Table 1. All sealers were prepared according to the manufacturers' advice.

\section{Test Microorganisms and Growth Conditions}

Antimicrobial activity of the root canal sealers was evaluated against S. aureus (ATCC 6538), E. faecalis (ATCC 29212), and C. albicans (10231; RSHSE, Ankara, Turkey). Microorganisms from frozen stock cultures were grown aerobically to a late logarithmic or early stationary phase in fresh brain heart infusion (BHI) broth.

\section{Agar Diffusion Test (ADT)}

In the ADT, root canal sealers were used only as a freshly mixed form. Fifty-one Mueller-Hinton plates were used for the ADT. Forty-eight plates were divided into 3 groups of 16 , according to the microorganism used. Each group was then divided into 4 subgroups for the 4 different root canal sealers. The remaining 3 positive control plates were streaked with 3 different bacteria or fungi, but no sealer was used. MuellerHinton agar was preferred as a medium for S. aureus and $E$. faecalis; Sabouraud agar was used for $C$. albicans. Three wells (6 $\mathrm{mm}$ in diameter) were formed in each agar plate. The $200 \mu \mathrm{L}$ of microbial suspension (approximately $10^{6} \mathrm{CFU} / \mathrm{ml}$ of each test microorganism were spread on the agar plates. Using a cavity liner applicator, $0.1 \mathrm{ml}$ of sealer was spread in the wells. Only one type of microorganism and root canal sealer was set to each agar plate. In total, 12 observation wells were used for each type of microorganism and root canal sealer. The plates were preserved at $37^{\circ} \mathrm{C}$ in a humid environment.

The plates were analyzed under $\times 2.5$ magnification loupes and evaluated for zones of inhibition, as evidenced by a lack of bacterial colonization around each well. The diameters of the established inhibition zones were measured in millimeters in two perpendicular locations for each sample and periodically recorded at 24 hours, 48 hours, 7 days, and 10 days. The samples were returned to incubation after each measurement.

\section{Direct Contact Test (DCT)}

In the DCT, both the freshly mixed forms and the set forms of the root canal sealers were tested separately on different plates. Microtiter plates with 96 wells were used. According to group, a cavity liner applicator was used to coat the wells with freshly mixed root canal sealers. According to the recommendations made by Cobankara et al, $10 \mu \mathrm{L}$ of microbial suspension (approximately $10^{6} \mathrm{CFU} / \mathrm{ml}$ ) were added to the root canal sealer surface about 20 minutes later (18). The prepared plates were stored at $37^{\circ} \mathrm{C}$ in a humid environment for 1 hour and it was ensured that there was direct contact between the test materials and microorganisms. Then fresh BHI broth $(245 \mu \mathrm{L})$ was added to each well and gently mixed for 2 minutes. Fifteen $\mu \mathrm{L}$ of the mixture was taken from each well of the first microtiter plate, this was then added to the second microtiter plate in an adjacent set of 8 wells 
containing fresh broth $(215 \mu \mathrm{m})$ and mixed. The second plate was used for optical density determinations. In a different microplate, microorganisms were cultivated without root canal sealers and served as a positive control group. To determine the optical density, the microplate spectrophotometer (BioTek, PowerWave XS2) was used for 16 different evaluation times within 24 hours. The kinetics of the outgrowth in each well was observed at $620 \mathrm{~nm}$. Before each reading, automixing was performed for each homogeneous microorganism suspension. In the set form group, the root canal sealers were mixed and left for 24 hours to completely set at $37^{\circ} \mathrm{C}$ and $100 \%$ humidity before the microorganism suspension was placed in contact with them. Other processes were similarly applied with the freshly mixed form group. The entire experiment was carried out under aseptic conditions.

\section{Statistical Analysis}

The statistical software SPSS 25.0 (IBM Corp. New York, NY, USA) was used to analyze the data. For the ADT, the Kolmogorov-Smirnov test was used to test the normality of distribution. The data in a normal distribution were analyzed using the analysis of variance (ANOVA) test and post-hoc comparisons were made with the Tukey test for ADT.

\section{Results}

\section{ADT}

The results of the ADT are shown in Table 2 . According to the ADT results, all sealers had antimicrobial activity against the tested microorganisms $(p<0.05)$ and no statistically significant correlation was found among antimicrobial effectiveness of the tested sealers and different time

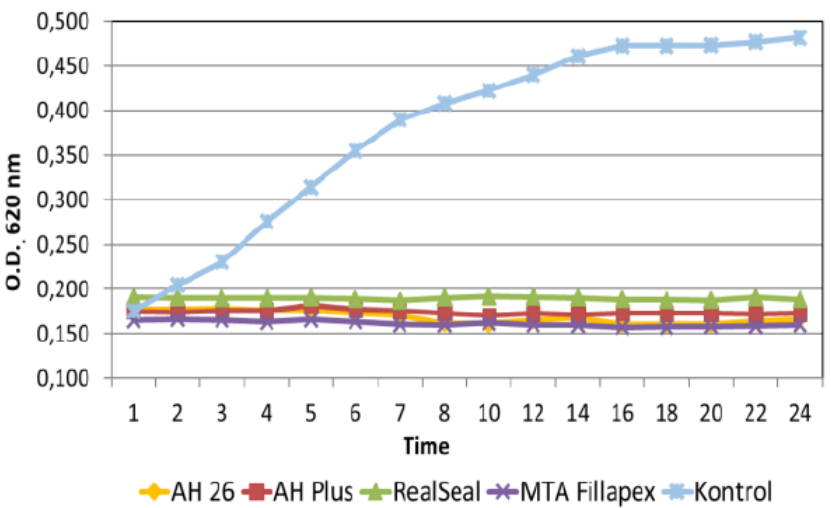

(a) intervals $(p>0.05)$ except for an MTA Fillapex and $E$. faecalis correlation which increased with time. Against S. aureus, there was no significant difference between $\mathrm{AH} 26$ and RealSeal; nor was there a significant difference between AH Plus and RealSeal ( $p>0.05$ ). These sealers showed a significant difference to MTA Fillapex sealers $(p<0.05)$. Against $E$. faecalis, AH 26 had the highest antibacterial activity $(p<0.05)$. The antibacterial activity of MTA Fillapex increased with time. There was no significant difference between RealSeal and MTA Fillapex ( $p>0.05)$ and AH plus had the lowest antibacterial activity. Against $C$. albicans, $\mathrm{AH} 26$ had the largest inhibition zone and showed the highest antifungal activity. AH Plus showed the lowest antifungal activity $(p<0.05)$. There was no significant difference between the RealSeal and MTA Fillapex sealers $(p>0.05)$. The three positive control plates showed bacterial or fungi growth.

\section{DCT}

The results of the DCT with the freshly mixed sealers are presented in Figures 1a, 2a, and 3a. Each curve includes 16 measurements taken within 24 hours. All sealers showed similar effectiveness for freshly mixed forms against all microorganisms. Freshly mixed samples of sealers showed complete inhibition of $S$. aureus, E. faecalis, and $C$. albicans. The results of the DCT with the 24-hour set forms of the sealers are presented in Figures 1b, 2b, and 3b. AH Plus has a similar antibacterial activity as the other sealers in the first 8 hours; after this time it began to lose its activity against $S$. aureus and $E$. faecalis. Additionally, both $\mathrm{AH}$ 26 and AH Plus could not inhibit fungal growth after 8 hours and microbial growth continued to increase. The 24-hour set samples of MTA Fillapex and RealSeal exhibited more stable antibacterial and antifungal activity against all microorganisms than the other sealers.

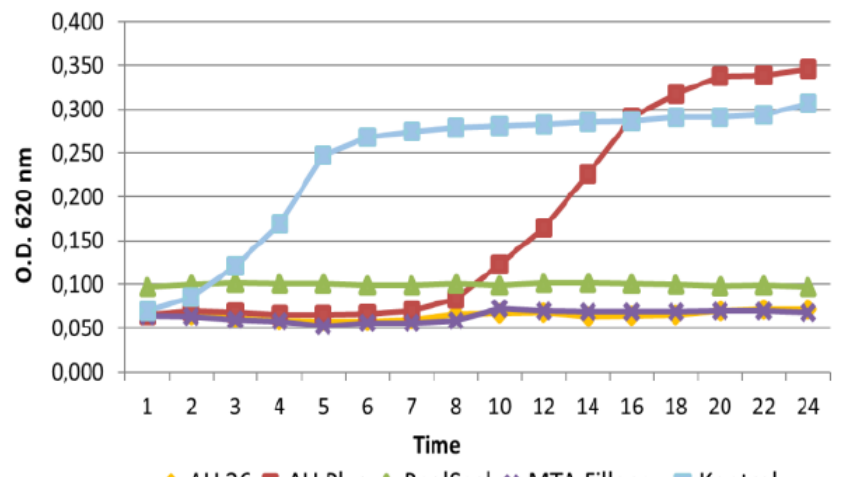

$\leadsto$ AH $26=$ AH Plus $\_$-RealSeal $\approx$ MTA Fillapex - Kontrol

Figure 1. Line graphs showing microbial growth curve of S. aureus after direct contact with fresh mixed sealers (a) and $24 \mathrm{~h}$ set sealers (b). Each point on the curve is the average optical density $\left(\mathrm{OD}_{620}\right)$ on a logarithmic scale measured in 8 separate wells at the same time. 


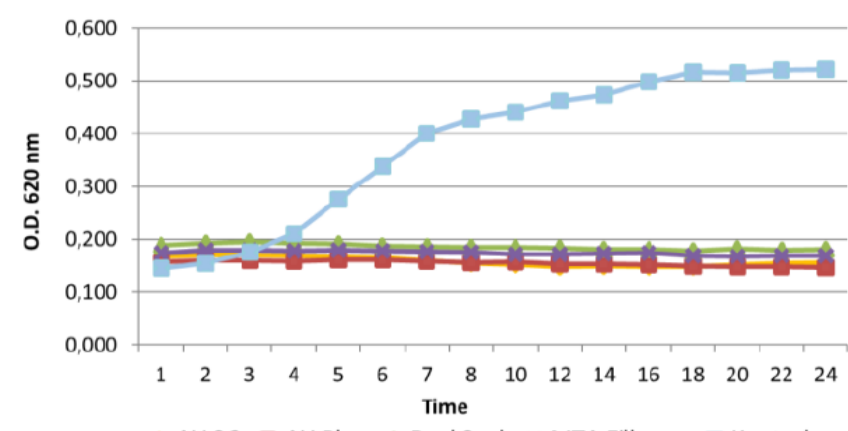

$\leadsto$ AH $26=$ AH Plus $\approx$ Real Seal $*$ MTA Fillapex $=$ Kontrol

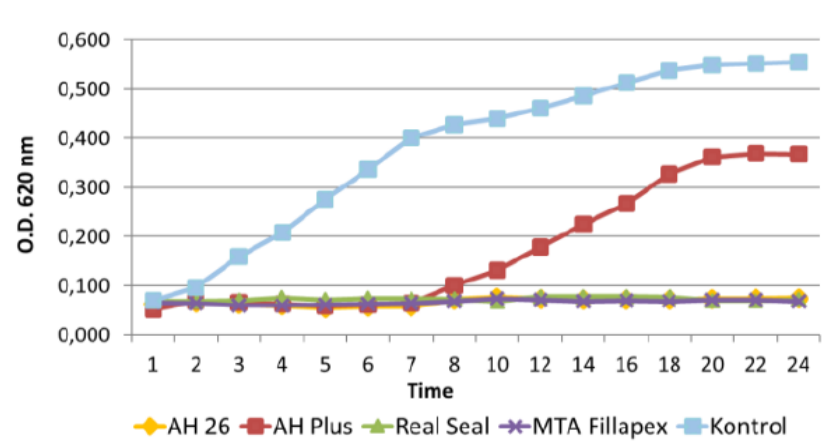

(b)

Figure 2. Line graphs showing microbial growth curve of $E$. faecalis after direct contact with fresh mixed sealers (a) and $24 \mathrm{~h}$ set sealers (b). Each point on the curve is the average optical density $\left(\mathrm{OD}_{620}\right)$ on a logarithmic scale measured in 8 separate wells at the same time.

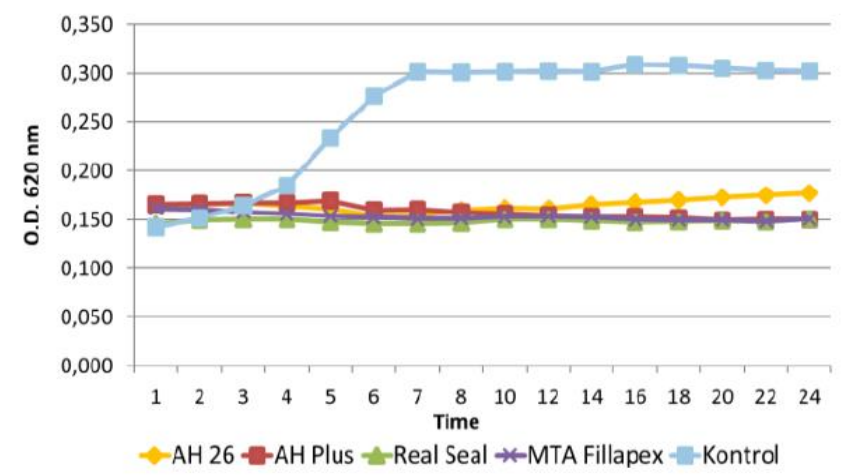

(a)

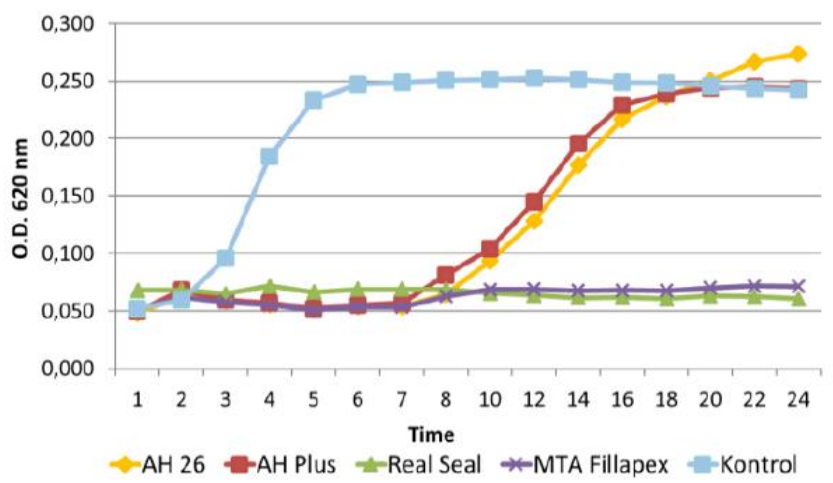

(b)

Figure 3. Line graphs showing microbial growth curve of $C$. albicans after direct contact with fresh mixed sealers (a) and $24 \mathrm{~h}$ set sealers (b). Each point on the curve is the average optical density $\left(\mathrm{OD}_{620}\right)$ on a logarithmic scale measured in 8 separate wells at the same time.

Table 1. Composition of sealers

\begin{tabular}{|c|c|c|}
\hline Sealers & Compositions & Manufacturer \\
\hline $\mathrm{AH} 26$ & $\begin{array}{l}\text { Paste A: Bisphenol-A epoxy resin, Bisphenol-F epoxy resin, } \\
\text { calcium tungstate, silica, zirconium oxide, iron oxide pigments } \\
\text { Paste B: Dibenzildiamin, aminoadamantane, trisiklodekan- diamine, calcium } \\
\text { tungstate, zirconium oxide, silica, silicon oil. }\end{array}$ & $\begin{array}{l}\text { Dentsply, De Trey, } \\
\text { Konstanz, Germany }\end{array}$ \\
\hline AH Plus & $\begin{array}{l}\text { Paste A: Diglycidil-bisphenol-A-ether, calcium tungsten, zirconium oxide, } \\
\text { aerosol, iron oxide. } \\
\text { Paste B: amina-1-adamantane, N,N-dibenzyl-5- oxanonandiamine-1,9, TCD- } \\
\text { di-amine, calcium tungsten, zirconium oxide, silicone oxide. }\end{array}$ & $\begin{array}{l}\text { Dentsply, De Trey, } \\
\text { Konstanz, Germany }\end{array}$ \\
\hline RealSeal & $\begin{array}{l}\text { Bis GMA, ethoxylated Bis GMA, urethane dimethacrylate, methacrylate, } \\
\text { calcium hydroxide, barium sulfate, barium glass, bismuth oxychloride, silica. }\end{array}$ & $\begin{array}{l}\text { SybronEndo, Orange, } \\
\text { USA }\end{array}$ \\
\hline MTA Fillapex & $\begin{array}{l}\text { Salicylate resin, diluting resin, natural resin, bismuth trioxide, } \\
\text { nanoparticulated silica, MTA, pigments. }\end{array}$ & $\begin{array}{c}\text { Angelus, Londrina, PR, } \\
\text { Brasil }\end{array}$ \\
\hline
\end{tabular}


Table 2. Inhibition zone measurement of microbial growth of sealers in periods $(\mathrm{mm})$

\begin{tabular}{ccccc}
\hline & AH 26 & AH Plus & RealSeal & MTA Fillapex \\
\hline S. aureus & & & & \\
\hline $24 \mathrm{~h}$ & $20.3 \pm 2.6^{\mathrm{a}}$ & $17.1 \pm 0.7^{\mathrm{b}}$ & $17.8 \pm 1.2^{\mathrm{b}}$ & $13.2 \pm 1.0^{\mathrm{c}}$ \\
\hline $48 \mathrm{~h}$ & $20.1 \pm 2.1^{\mathrm{a}}$ & $17.1 \pm 0.7^{\mathrm{b}}$ & $18.7 \pm 2.1^{\mathrm{a}, \mathrm{b}}$ & $13.1 \pm 1.0^{\mathrm{c}}$ \\
\hline 7 days & $19.8 \pm 2.0^{\mathrm{a}}$ & $17.3 \pm 0.6^{\mathrm{b}}$ & $18.8 \pm 2.0^{\mathrm{a}, \mathrm{b}}$ & $13.3 \pm 0.9^{\mathrm{c}}$ \\
\hline 10 days & $19.8 \pm 1.8^{\mathrm{a}}$ & $17.2 \pm 0.6^{\mathrm{b}}$ & $19.5 \pm 1.3^{\mathrm{a}}$ & $13.1 \pm 1.0^{\mathrm{c}}$ \\
\hline E. faecalis & & & \\
\hline $24 \mathrm{~h}$ & $20.3 \pm 0.9^{\mathrm{a}}$ & $12.8 \pm 1.1^{\mathrm{c}}$ & $18.3 \pm 2.2^{\mathrm{b}}$ & $13.6 \pm 0.9^{\mathrm{c}}$ \\
\hline $48 \mathrm{~h}$ & $19.9 \pm 1.3^{\mathrm{a}}$ & $12.7 \pm 1.2^{\mathrm{d}}$ & $17.3 \pm 0.9^{\mathrm{b}}$ & $15.0 \pm 0.8^{\mathrm{c}}$ \\
\hline 7 days & $20.9 \pm 0.7^{\mathrm{a}}$ & $13.2 \pm 1.0^{\mathrm{c}}$ & $17.7 \pm 1.0^{\mathrm{b}}$ & $17.7 \pm 1.3^{\mathrm{b}}$ \\
\hline 10 days & $21.0 \pm 1.1^{\mathrm{a}}$ & $13.1 \pm 1.0^{\mathrm{c}}$ & $17.9 \pm 0.9^{\mathrm{b}}$ & $17.2 \pm 1.2^{\mathrm{b}}$ \\
\hline C. albicans & & & & \\
\hline $24 \mathrm{~h}$ & $39.5 \pm 1.5^{\mathrm{a}}$ & $12.4 \pm 0.6^{\mathrm{c}}$ & $17.6 \pm 0.6^{\mathrm{b}}$ & $18.4 \pm 2.2^{\mathrm{b}}$ \\
\hline $48 \mathrm{~h}$ & $41.1 \pm 2.4^{\mathrm{a}}$ & $12.3 \pm 0.4^{\mathrm{d}}$ & $17.3 \pm 0.6^{\mathrm{c}}$ & $19.3 \pm 1.9^{\mathrm{b}}$ \\
\hline 7 days & $39.4 \pm 1.6^{\mathrm{a}}$ & $12.6 \pm 0.7^{\mathrm{d}}$ & $17.6 \pm 0.8^{\mathrm{c}}$ & $19.4 \pm 1.6^{\mathrm{b}}$ \\
\hline 10 days & $40.2 \pm 1.3^{\mathrm{a}}$ & $12.6 \pm 0.7^{\mathrm{c}}$ & $17.6 \pm 0.7^{\mathrm{b}}$ & $18.9 \pm 1.8^{\mathrm{b}}$ \\
\hline
\end{tabular}

\section{Discussion}

Root canal treatment reduces microorganisms in the root canal, but it does not eliminate all of them. Microorganisms can persist in the isthmus, dentinal tubules, lateral canals and apical ramifications after root canal treatments have been informed (19). Microorganisms may persist in these areas and may reproduce. This results in a complete failure of the root canal treatment. Sealers that exhibit both excellent sealing and antibacterial properties can be used to improve the success rate of endodontic treatment. Using sealers with antimicrobial properties can be advantageous against persistent residual infection and bacteria reentering from the oral cavity (20).

This study investigated the antibacterial and antifungal properties of a new generation of root canal sealer against widely used or accepted root canal sealers.

S. aureus is one of the standard microorganisms that is used in antimicrobial activity tests of endodontic materials (21). E. faecalis has a high prevalence in persistent endodontic infections. It has a collagenbinding protein that allows it to bond to root canal dentine (22), so it is difficult to remove. Peciuliene et alshowed the isolation of $E$. faecalis and $C$. albicans in root-filled teeth with persistent apical periodontitis (23). C. albicans can form a biofilm similar to $E$. faecalis. In a study that used the polymerase chain reaction (PCR) technique, the presence of $C$. albicans was reported in 5 of 24 isolations from the root canals in primary infections (8). In secondary infections, it was identified in 6 of 33 samples; 3 of these 6 cases were identified with $E$. faecalis (23). Therefore, it should be noted that determining the antifungal activity of root canal sealers is important in order to enhance the treatment's success. Consequently, because of their common pathogenic disaster, these 3 microorganisms were preferred to be used for the tests.

In the ADT, freshly mixed root canal sealers were used. The DCT was performed to analyze both fresh and 24-hour set forms of root canal sealers. The ADT assays have been a semi-quantitative technique to determine the antimicrobial activities of dental materials. The ADT has some limitations: results are highly influenced by the solubility and diffusion ability of the material, and also do not distinguish between bacteriostatic or bactericidal properties of the tested materials (24). Nawal et al. (25) indicate that, when new materials are tested, more than 1 method should be used. Some studies about antimicrobial activity have preferred to use ADT together with DCT to overcome or minimalize its disadvantages or limitations $(16,26)$.

The DCT is based on evaluating the effect of direct and close contact between the tested materials and microorganisms on microbial outgrowth; it also provides significant advantages including reproducibility, simultaneous testing of samples, quantitative assay, and continuous measurements of bacterial outgrowth (17). It is independent of the diffusion and solubility properties of the media and tested material and the effect of sealers at different levels of setting reaction can be evaluated (27). The increase in the optical density value in DCT indicates that the number of bacteria in the environment increases. An increase in the number of bacteria is interpreted as a decrease in the antimicrobial activity of the tested material. 
In the ADT, AH 26 showed the highest antimicrobial activity on all tested microorganisms. AH 26 contains formaldehyde and it is thought that high antimicrobial activity occurs when this substance is released (28). MTA Fillapex showed higher antibacterial and antifungal effects than AH Plus against $E$. faecalis and $C$. albicans respectively. Similarly, Poggio et al. (29) reported that AH Plus showed a low antibacterial effect against $E$. faecalis and $C$. albicans in the ADT. When MTA Fillapex was compared with RealSeal, it had a lower antibacterial effect against only $S$. aureus and showed a similar effect against the others. These results are important because of the inadequate published articles comparing a methacrylate resin sealer with MTA-based sealer.

Pizzo et al. (27) reported that, in a DCT, only fresh AH Plus showed antibacterial activity and 24-hour and 7-day set samples did not show effectiveness against $E$. faecalis. Similarly, in the present study, AH 26 and $\mathrm{AH}$ Plus set forms were not effective against some microorganisms over longer periods. Eldeniz et al. reported that 3-day aging of root-end filling materials had a variable antibacterial activity and emphasized that, when the specimens were aged in a $100 \%$ humidity environment at $37^{\circ} \mathrm{C}$, this allowed continued release of antibacterial components (30).

In this study, freshly mixed and 24-hour set form samples of MTA Fillapex and RealSeal exhibited greater antibacterial activity against all microorganisms than the other sealers. MTA consists of $50-75 \%$ calcium oxide by weight. When water is added, the cement hydrates to silicate hydrate gel and calcium hydroxide (31). It can be supposed that MTA and calcium hydroxide may have a similar degree of activity. The release of hydroxyl ions from calcium hydroxide $\left(\mathrm{Ca}(\mathrm{OH})_{2}\right)$ to the hydrous environment creates antimicrobial activity. Hydroxyl ions are highly oxidant free radicals that exhibit severe reactivity with several biomolecules (2). They play an important role in the elimination of bacteria, causing an increase in $\mathrm{pH}$. A pH greater than 9 may reversibly or irreversibly influence the cellular membrane enzymes of microorganisms and results in the loss of biological activity (32).

MTA Fillapex has a high solubility, $\mathrm{pH}$, and calcium ion release (33). Faria-Junior et al. compared the $\mathrm{pH}$ and solubility of MTA Fillapex with several root canal sealers and reported a pH rise to 10.06 after 15 hours of immersion in deionized water (34). Similarly, it was shown that the $\mathrm{pH}$ value of MTA after mixing was 10.2 which increased to 12.5 after 3 hours (35). In a study, MTA Fillapex showed antibacterial effect over 7 days and the $\mathrm{pH}$ value was between 10.14 and 10.50 (16). It is thought that this high $\mathrm{pH}$ and solubility may contribute to the antibacterial activity of MTA Fillapex.

The physicochemical properties of a root canal sealer were combined with the biological advantages of MTA and MTA Fillapex was produced. The composition of MTA Fillapex contains mineral trioxide aggregate, salicylate resin, natural resin, bismuth, and silica. MTA Fillapex has an antimicrobial mechanism due to its MTA substance.

In root canal therapy, moisture remaining in the tubules and on the root dentin surface after root canal irrigation affects the sealing ability of traditional hydrophobic sealers (33). This problem can be solved using a hydrophilic sealer. MTA Fillapex is a hydrophilic material similar to MTA (2). Hydrophilic materials can increase sealing ability and support antimicrobial activity (36).

\section{Conclusions}

The results of the present study showed that all tested sealers had antibacterial and antifungal activity on the tested microorganisms in the ADT. But in the DCT, 24-hour set forms of $\mathrm{AH} 26$ and AH Plus lost their antimicrobial activity over time. This can be attributed to a diminished release of the antimicrobial component from the tested sealers. MTA Fillapex showed suitable antimicrobial properties to be used as an endodontic sealer.

Ethical Approval: Ethics committee approval was not obtained because no material or radiographs of human or animal origin were studied.

Peer-review: Externally peer-reviewed.

Author Contributions: Conception - A.T.; Design - A.T., A.E.; Supervision - A.T.; Materials - A.E.; Data Collection and/or Processing - A.T., A.E.; Analysis and/or Interpretation - A.T.; Literature Review A.T., A.E.; Writer - A.T., A.E.; Critical Review - A.E.

Conflict of Interest: No conflict of interest was declared by the authors.

Financial Disclosure: This research, as part of PhD study of Dr. Ali Turkyilmaz, was supported by Scientific Research Projects Coordination Center (Project number: 2012/94) of Kirikkale University, Kirikale/Turkey.

Acknowledgements: The authors wish to express sincere appreciation to KÜBTÜAM for kind cooperation and help.

\section{References}

1. Ng YL, Mann V, Rahbaran S, Lewsey J, Gulabivala K. Outcome of primary root canal treatment: systematic review of the literature - Part 2. Influence of clinical factors. Int Endod J 2008; 41: 6-31. (Crossref)

2. Mohammadi Z, Giardino L, Palazzi F, Shalavi S. Antibacterial activity of a new mineral trioxide aggregate-based root canal sealer. Int Dent J 2012; 62: 70-3. (Crossref)

3. Gomes BP, Ferraz CC, Vianna ME, Rosalen PL, Zaia AA, Teixeira $F B$, et al. In vitro antimicrobial activity of calcium hydroxide pastes and their vehicles against selected microorganisms. Braz Dent J 2002; 13: 155-61. (Crossref)

4. Smith AJ, Robertson D, Tang MK, Jackson MS, MacKenzie D, Bagg J. Staphylococcus aureus in the oral cavity: a three-year retrospective analysis of clinical laboratory data. Br Dental J 2003; 195: 701-3. (Crossref) 
5. Stuart CH, Schwartz SA, Beeson TJ, Owatz CB. Enterococcus faecalis: its role in root canal treatment failure and current concepts in retreatment. J Endod 2006; 32: 93-8. (Crossref)

6. Portenier I, Waltimo TMT, Haapasalo M. Enterococcus faecalis: the root canal survivor and "star" in post-treatment disease. Endod Topics 2003; 6: 135-59. (Crossref)

7. Siqueira JF, Sen BH. Fungi in endodontic infections. Oral Surg Oral Med Oral Pathol Oral Radiol Endod 2004; 97: 632-41. (Crossref)

8. Baumgartner JC, Watts CM, Xia T. Occurrence of Candida albicans in infections of endodontic origin. J Endod 2000; 26: 695-8. (Crossref)

9. Waltimo TM, Siren EK, Torkko HL, Olsen I, Haapasalo MP. Fungi in therapy-resistant apical periodontitis. Int Endod J 1997; 30: 96-101. (Crossref)

10. Kaplan AE, Picca M, Gonzalez MI, Macchi RL, Molgatini SL. Antimicrobial effect of six endodontic sealers: an in vitro evaluation. Endod Dent Traumatol 1999; 15: 42-5.(Crossref)

11. Bin CV, Valera MC, Camargo SE, Rabelo SB, Silva GO, Balducci I, et al. Cytotoxicity and genotoxicity of root canal sealers based on mineral trioxide aggregate. J Endod 2012; 38: 495500. (Crossref)

12. Lodiene G, Morisbak E, Bruzell E, Orstavik D. Toxicity evaluation of root canal sealers in vitro. Int Endod J 2008; 41: 72-7.

13. Assmann E, Scarparo RK, Böttcher DE, Grecca FS. Dentin bond strength of two mineral trioxide aggregate-based and one epoxy resin-based sealers. J Endod 2012; 38: 219-21. (Crossref)

14. Sungur DD, Altundasar E, Uzunoglu E, Yilmaz Z. Influence of different final irrigation regiment and various endodontic filling materials on vertical root canal fracture resistance. Niger J Clin Pract 2016; 19: 267-71. (Crossref)

15. Borges RP, Sousa- Neto MD, Versiani MA, Rached-Junior FA, DeDeus G, Miranda CE, et al. Changes in the surface of four calcium silicate-containing endodontic materials and an epoxy resin - based sealer after a solubility test. Int Endod J 2012; 45: 419-28. (Crossref)

16. Morgental RD, Vier-Pelisser FV, Oliveira SD, Antunes FC, Cogo DM, Kopper PM. Antibacterial activity of two MTA-based root canal sealers. Int Endod J 2011; 44: 1128-33. (Crossref)

17. Weiss El, Shalhav M, Fuss Z. Assessment of antibacterial activity of endodontic sealers by a direct contact test. Endod Dent Traumatol 1996; 12: 179-84. (Crossref)

18. Cobankara FK, Altinöz HC, Ergani O, Kav K, Belli S. In vitro antibacterial activities of root-canal sealers by using two different methods. J Endod. 2004; 30: 57-60. (Crossref)

19. Spangberg L, Haapasalo H. Rationale and efficacy of root canal medicaments and root filling materials with emphasis on treatment outcome. Endod Topics 2002; 2: 35-58. (Crossref)

20. Orstavik D. Antibacterial properties of root canal sealers, cements and pastes. Int Endod J 1981; 14: 125-33. (Crossref)

21. Lai CC, Huang FM, Yang HW, Chan Y, Huang MS, Chou MY, Chang YC. Antimicrobial activity of four root canal sealers against endodontic pathogens. Clin Oral Investig 2001; 5: 236-9. (Crossref)

22. Hubble TS, Hatton JF, Nallapareddy SR, Murray BE, Gillespie MJ. Influence of Enterococcus faecalis proteases and the collagen-binding protein, Ace, on adhesion to dentin. Oral Microbiol Immunol 2003; 18: 121-6. (Crossref)

23. Peciuliene V, Reynaud AH, Balciuniene I, Haapasalo M. Isolation of yeasts and enteric bacteria in root-filled teeth with chronic apical periodontitis. Int Endod J 2001; 34: 429-34. (Crossref)

24. Pizzo G, Giammanco GM, Cumbo E, Nicolosi G, Gallina G. In vitro antibacterial activity of endodontic sealers. J Dent 2006; 34: 35-40. (Crossref)

25. Nawal RR, Parande M, Sehgal R, Naik A, Rao NR. A comparative evaluation of antimicrobial efficacy and flow properties for Epiphany, Guttaflow and AH-Plus sealer. Int Endod J 2011; 44: 307-13. (Crossref)

26. Eldeniz AU, Erdemir A, Hadimli HH, Belli S, Erganis 0. Assessment of antibacterial activity of EndoREZ. Oral Surg Oral Med Oral Pathol Oral Radiol Endod 2006; 102: 119-26. (Crossref)

27. Pizzo, G, Giammanco GM, Cumbo E, Nicolosi G, Gallina G. In vitro antibacterial activity of endodontic sealers. J Dent, 2006. 34: 35-40. (Crossref)

28. Mickel AK, Nguyen TH, Chogle S. Antimicrobial activity of endodontic sealers on Enterococcus faecalis. J Endod, 2003; 29: 257-8. (Crossref)

29. Poggio C, Lombardini M, Colombo M, Dagna A, Saino E, Arciola $\mathrm{CR}$, et al. Antibacterial effects of six endodontic sealers. Int $\mathrm{J}$ Artif Organs 2011; 34: 908-13. (Crossref)

30. Eldeniz AU, Hadimli HH, Ataoglu H, Orstavik D. Antibacterial effect of selected root-end filling materials. J Endod 2006; 32: 345-9. (Crossref)

31. Roberts HW, Toth JM, Berzins DW, Charlton DG. Mineral trioxide aggregate material use in endodontic treatment: a review of the literature. Dent Mater 2008; 24: 149-64. (Crossref)

32. Estrela C, Sydney GB, Bammann LL, Felippe Junior O. Mechanism of action of calcium and hydroxyl ions of calcium hydroxide on tissue and bacteria. Braz Dent J 1995; 6: 85-90.

33. Borges RP, Sousa-Neto MD, Versiani MA, Rached-Hunior FA, DeDeus G, Miranda CE, et al. Changes in the surface of four calcium silicate-containing endodontic materials and an epoxy resin-based sealer after a solubility test. Int Endod J 2012; 45: 419-28. (Crossref)

34. Faria-Junior NB, Tanomaru-Filho M, Berbert FL, GuerreiroTanomaru JM. Antibiofilm activity, $\mathrm{pH}$ and solubility of endodontic sealers. Int Endod J 2013; 46: 755-62. (Crossref)

35. Torabinejad M, Hong CU, MCDonald F, Pitt Ford TR. Physical and chemical properties of a new root-end filling material. J Endod 1995; 21: 349-53. (Crossref)

36. Roggendorf MJ, Ebert J, Petschelt A, Frankenberger R. Influence of moisture on the apical seal of root canal fillings with five different types of sealer. $\mathrm{J}$ Endod 2007; 33: 31-3. (Crossref) 